Artigo / Article

\title{
Influência da coleta, da produção e da estocagem na qualidade dos concentrados de plaquetas
}

\section{Influence of collection, preparation and storage on the quality of platelet concentrates}

\author{
Maria Aparecida V. Tostes ${ }^{1}$ \\ Sebastião Tostes Junior ${ }^{2}$ \\ Gilberto A. Pereira ${ }^{3}$ \\ Sheila Soares ${ }^{4}$ \\ Helio Moraes-Souza ${ }^{5}$
}

\begin{abstract}
Como o controle de qualidade dos concentrados de plaquetas (CP), feito na data de seu vencimento, não possibilita distinguir o momento e o procedimento que determina a eventual redução de sua qualidade, decidimos investigar, separadamente, a influência da coleta, da produção e da estocagem sobre a qualidade deste hemocomponente. Foram avaliados, em 33 CP randômicos, diariamente, durante cinco dias, os seguintes parâmetros: a agregação, o número de plaquetas e leucócitos, a $\mathrm{pO}_{2}$ e $\mathrm{pCO}_{2}$ o $\mathrm{pH}$, sódio e potássio, a presença de swirling, grumos, hemácias e lipemia e cultura para bactérias. Observamos maior queda da agregação plaquetária com pares de agonistas durante a produção dos CP (de 99,4\% para 59,8\%, p<0,01), seguida de queda gradativa durante a estocagem, atingindo $40,4 \%$ no quinto dia. Durante o período de estocagem observamos também: 1. queda gradativa da concentração de plaquetas $(p<0,05)$, porém com valores sempre maiores que $5 \times 10^{10} / 70 \mathrm{~mL} ; 2$. diminuição da concentração de leucócitos ( $p<0,05)$; 3. aumento da $\mathrm{pO}_{2}$ e queda da $\mathrm{pCO}_{2}(\mathrm{p}<0,05)$; 4. aumento do $\mathrm{pH}(\mathrm{p}<0,05$ a partir do quarto dia) e da concentração de sódio e de potássio (em geral $p<0,05$ ); 5. swirling em todos os $C P$, grumos plaquetários em apenas um e ausência de hemácias e de lipemia em todos; e 6. negatividade das culturas para bactérias. Os resultados demonstram que as alterações foram mais evidentes no processo de produção e sugerem que o controle de qualidade dos $C P$ deve contemplar da coleta a final do periodo de estocagem. Rev. Bras. Hematol. Hemoter. 2008;30(5):367-373.
\end{abstract}

Palavras-chave: Transfusão de plaquetas; agregação plaquetária; controle de qualidade.

\section{Introdução}

As plaquetas são pequenos fragmentos do citoplasma dos megacariócitos e, quando ativadas, se aderem ao endotélio vascular lesado e/ou a outras plaquetas, formando agregados que têm como função a prevenção ou a interrupção do sangramento. ${ }^{1} \mathrm{Na}$ hemoterapia, o seu emprego é feito sob a forma de concentrados de plaquetas $(\mathrm{CP})$, que permitem infundir grandes quantidades destas em pequenos volu- mes, e são indicados especialmente para pacientes trombocitopênicos por déficit na produção medular, ou submetidos a grandes cirurgias. ${ }^{2} \mathrm{Os} \mathrm{CP}$ podem ser obtidos pelos processadores automáticos de células sangüíneas pelo sistema de aférese, ou como unidades randômicas, a partir de unidades individuais de sangue total, pelos métodos do buffy coat ou do plasma rico em plaquetas (PRP). ${ }^{3}$

Para garantir a eficácia esperada em uma transfusão de $\mathrm{CP}$ é fundamental a preservação da sua função hemostática.

${ }^{1}$ Técnica do Laboratório da Universidade Federal do Triângulo Mineiro (UFTM) - Uberaba-MG.

${ }^{2}$ Professor Adjunto da Disciplina de Medicina Legal da UFTM.

${ }^{3}$ Professor Assistente da Disciplina de Bioestatística da UFTM.

${ }^{4}$ Professora Adjunta da Disciplina de Hematologia e Hemoterapia da UFTM.

${ }^{5}$ Professor Titular da Disciplina de Hematologia e Hemoterapia da UFTM.

Correspondência: Maria Aparecida Vieira Tostes

Universidade Federal do Triângulo Mineiro

Av. Getúlio Guarita, $250-4^{\circ}$ andar - Abadia

38025-440 - Uberaba-MG - Brasil

Tel: 553433125077

E-mail:vieiratostes@terra.com.br 
Nos processos de coleta, de produção e de estocagem deste hemocomponente, as plaquetas são expostas a vários estímulos mecânicos e químicos que podem levar à sua ativação e, além disso, durante o período de estocagem, um crescente número de plaquetas chega ao final de sua vida, que é de 12 a 15 dias. Contribui para este processo a crescente produção de metabólicos durante a estocagem, gerando meio desfavorável à viabilidade plaquetária. Em conjunto, essas alterações acabam por diminuir a atividade hemostática dos CP. ${ }^{4}$

$\mathrm{O}$ controle de qualidade dos hemocomponentes é o mecanismo utilizado nos hemocentros para verificar o potencial hemostático dos CP e para correção de eventuais intercorrências. No Brasil, preconiza-se a sua realização na data de vencimento dos mesmos, ${ }^{5}$ o que não permite definir o momento e, sobretudo, o procedimento que determinou a eventual redução ou perda da sua capacidade hemostática. Isto posto, necessário se faz definir a influência de cada etapa do processamento, buscando subsídios para a melhoria da qualidade deste hemocomponente.

O objetivo deste trabalho é avaliar a eventual interferência da coleta, da produção (fracionamento) e da estocagem sobre a qualidade dos concentrados de plaquetas obtidos pelo método do PRP.

\section{Material e Método}

A pesquisa foi iniciada após a aprovação do projeto pelo Comitê de Ética em Pesquisa da Universidade Federal do Triângulo Mineiro, o qual é registrado junto à Comissão Nacional de Ética em Pesquisa (Conep/MS). ${ }^{6}$

\section{Material}

As amostras de sangue foram obtidas de 33 doadores do Hemocentro Regional de Uberaba, após o consentimento livre e esclarecido, sendo incluídos em cada dia de experimento os primeiros que preenchessem as seguintes exigências: 1 . estar apto para doação de plaquetas 5 ; 2 ser do sexo masculino; 3. apresentar veias calibrosas e de fácil punção; 4. tempo de coleta inferior a 10 minutos; 5 . volume de sangue total colhido de $450 \mathrm{~mL}( \pm 20 \mathrm{~mL})$ e 6 . apresentar, na amostra colhida em tubo com CPDA1 na proporção de 1:10, entre 200 e 400 mil plaquetas por $\mathrm{mm}^{3}$.

De cada doador foram obtidos três tipos de amostras: 1) STD (Sangue Total do Doador) obtido em $\mathrm{CPDA}_{1}$, concentração final de 1:10;2) STB (Sangue Total da Bolsa) retirado da bolsa tripla de cinco dias com CPDA 1 com $450 \pm 20 \mathrm{~mL}$ de sangue e 3) CP (Concentrados de Plaquetas não deleucotizados). O STD foi obtido diretamente do doador através do tubo coletor da bolsa ("macarrão"), após sua secção, e o STB foi obtido diretamente de bolsa, através do "macarrão", logo após a coleta. A centrifugação da bolsa com o sangue total a $22^{\circ} \mathrm{C}$ e $679 \mathrm{~g}$ durante dez minutos deu origem ao Plasma Rico em Plaquetas (PRP); este, submetido à centrifugação a $22^{\circ} \mathrm{C}$ e $2.040 \mathrm{~g}$ por dez minutos, deu origem aos $\mathrm{CP}$ e ao e ao Plasma Pobre em Plaquetas (PPP). Da massa total de cada bolsa de CP foi descontada a massa da bolsa vazia, previa- mente conhecida, ajustando-se então a massa líquida para 70 gramas, equivalendo a $70 \mathrm{~mL}$. As bolsas de CP foram mantidas em repouso por uma hora e então colocadas em agitador, com 8 a 12 rpm e à temperatura de $22 \pm 2^{\circ} \mathrm{C}$.

Os testes de agregação do STD e do STB foram realizados até 4 horas após a coleta do sangue. Os testes nos CP (contagem de plaquetas e de leucócitos, agregação e avaliação de $\mathrm{pO}_{2}, \mathrm{pCO}_{2}, \mathrm{pH}$, concentração de sódio e de potássio, swirling e presença de grumos, de hemácias e de lipemia) foram realizados 4, 24, 48, 72, 96 e 120 horas após a produção; no quinto dia (120 horas após a produção) foi feita também a cultura para bactérias.

\section{Agregação plaquetária in vitro}

O teste foi realizado segundo a técnica turbidométrica, ${ }^{7}$ em agregômetro da Chrono-Log Corporation, USA, modelo 500-VS. Amostras do STD e do STB foram centrifugados, originando PRP os quais, como o $\mathrm{CP}$, tiveram o número de plaquetas ajustado para $2 \times 10^{5}$ plaquetas $/ \mathrm{mm}^{3}$ com PPP homólogo. Estas amostras ajustadas foram submetidas à ação dos pares de agonistas: ácido aracdônico (concentração final 5,5 $\mu \mathrm{mol}$ )/adenosina difosfato (concentração final de $1,25 \mu \mathrm{mol}$ ) e ácido aracdônico (concentração final 5,5 $\mu \mathrm{mol}$ )/ adrenalina (concentração final de 1,25 $\mu \mathrm{mol}$ ). A curva de agregação foi registrada através do canal óptico do agregômetro, ${ }^{7}$ o qual foi calibrado com PRP e PPP de cada amostra avaliada. Antes da adição dos agonistas aguardaram-se cinco minutos para verificação de agregação espontânea.

\section{Concentração de plaquetas}

As plaquetas foram contadas em câmara de Neubauer após diluição em oxalato de amônio $(1: 80)^{8,9} \mathrm{e}$ os resultados foram expressos em $10^{10}$ plaquetas $/ 70 \mathrm{~mL}$ de CP.

\section{Concentração de leucócitos}

Os leucócitos também foram contados em câmara de Neubauer, com diluição em solução de Turk (1:50), ${ }^{9}$ e os resultados foram expressos em $10^{8}$ leucócitos $/ 70 \mathrm{~mL}$ de CP.

$p O_{2}, p C O_{2}, p H$ e concentração de sódio e de potássio

Foram feitas por método eletrônico em equipamento da Bayer (Bayer - Rapidlab, Mod 348), à temperatura de $37^{\circ} \mathrm{C}$. Os resultados foram expressos em $\mathrm{mmHg}\left(\mathrm{pO}_{2}\right.$ e $\left.\mathrm{pCO}_{2}\right)$ e em $\mathrm{mEq} / \mathrm{L}$ (sódio e potássio).

Aspecto visual (swirling, grumos, hemácias e lipemia) e cultura para bactérias

A análise foi feita enquanto se movimentava a bolsa por inversão contra uma fonte de luz e os resultados foram expressos em presente ou ausente. ${ }^{10-13}$

A cultura para bactérias foi feita em meio ágar-sangue, em placa de Petri. 
Análise estatística

Inicialmente os dados foram avaliados quanto à suposição de normalidade da sua distribuição pelo teste de Kolmogorov-Smirnov, sendo tomados para análise paramétrica os que se mostraram normais $(\mathrm{p}>0,2)$. Também foram tomados aqueles cujos coeficientes de variação (desvio padrão x 100/média) foram menores de $15 \%$ e a distribuição gráfica não mostrou intensa assimetria; os demais dados foram transformados $(1 / \log \mathrm{x})$ para restabelecer essas características.

Para verificar a partir de qual momento as variáveis de interesse começaram a apresentar diferenças, aplicamos análise de variância (ANOVA-F) para medidas repetitivas, seguidas do teste de comparação múltipla de Duncan. Para o estudo da associação entre variáveis de interesse foi calculado o coeficiente de correlação linear. O nível de significância adotado foi de $5 \%(\mathrm{p}<0,05)$.

\section{Resultados}

Agregação plaquetária in vitro

Não houve agregação espontânea. Com o par de agonistas ácido aracdônico (AA)/adrenalina (ADR), a agrega- ção plaquetária foi de $100 \pm 0,0 \%$ no STD e de $99,4 \pm 2,5 \%$ no STB, caindo para $59,8 \pm 11,6 \%$ logo após o processo de produção dos CP (às 4 horas). Esta queda continuou menos intensamente durante a estocagem, chegando a 40,4 $\pm 7,7 \%$ ao final de 120 horas. A média, o desvio padrão, a mediana e valores máximos e mínimos nos diversos momentos analisados, bem como os testes de comparação múltipla de Duncan, estão na tabela 1 e na figura 1. A agregação com o par de agonistas ácido aracdônico (AA)/adenosina difosfato (ADP) apresentaram resultados semelhantes. Figura 2.

Concentração de plaquetas dos CP

A concentração de plaquetas nos CP diminuiu ao longo do período de estocagem, caindo de 7,5( $\pm 0,3) \times 10^{10} / 70 \mathrm{~mL}$ às 4 horas para $6,3( \pm 0,3) \times 10^{10} / 70 \mathrm{~mL}$ às 120 horas, sendo essa diminuição estatisticamente significante em todos os intervalos (Tabela 2 e Figura 3).

\section{Concentração de leucócitos dos $C P$}

Houve diminuição estatisticamente significante do número de leucócitos durante a estocagem dos $\mathrm{CP}$, caindo de $0,53( \pm 0,09) \times 10^{8} / 70 \mathrm{~mL}$ às 4 horas, para $0,28( \pm 0,08) \times 10^{8} /$ $70 \mathrm{~mL}$ às 120 horas $(\mathrm{p}<0,01)$.

Tabela 1. Medidas descritivas das porcentagens da agregação plaquetária (média e desvio padrão; valor mínimo, mediana e valor máximo) de 33 doadores, com os agonistas AA e ADR, nos plasmas ricos de plaquetas obtidos do STD, do STB e dos CP, nos vários tempos de estocagem, em horas, e o resultado do teste de comparação de Duncan

\begin{tabular}{rcccccccc}
\hline & STD & STB & CP4h & CP24h & CP48h & CP72h & CP96h & CP120h \\
\cline { 2 - 9 } & $100 \pm 0,0$ & $99,4 \pm 2,5$ & $59,8 \pm 11,6$ & $56,6 \pm 10,0$ & $54,6 \pm 11,3$ & $50,3 \pm 10,0$ & $44,0 \pm 9,8$ & $40,4 \pm 7,7$ \\
& $100(100) 100$ & $87,5(100) 100$ & $27(61) 77$ & $22(60) 72$ & $22(52) 72$ & $30(53) 66$ & $22(46) 66$ & $22(40) 51$ \\
\hline STB & - & - & $<0,01$ & $<0,01$ & $<0,01$ & $<0,01$ & $<0,01$ & $<0,01$ \\
CP4h & - & - & - & 0,02 & $<0,01$ & $<0,01$ & $<0,01$ & $<0,01$ \\
CP24h & - & - & - & - & 0,15 & $<0,01$ & $<0,01$ & $<0,01$ \\
CP48h & - & - & - & - & - & $<0,01$ & $<0,01$ & $<0,01$ \\
CP72h & - & - & - & - & - & - & $<0,01$ & $<0,01$ \\
CP96h & - & - & & & & & - & $<0,01$ \\
\hline
\end{tabular}

Média \pm Desvio padrão

Mínimo (mediana) Máximo

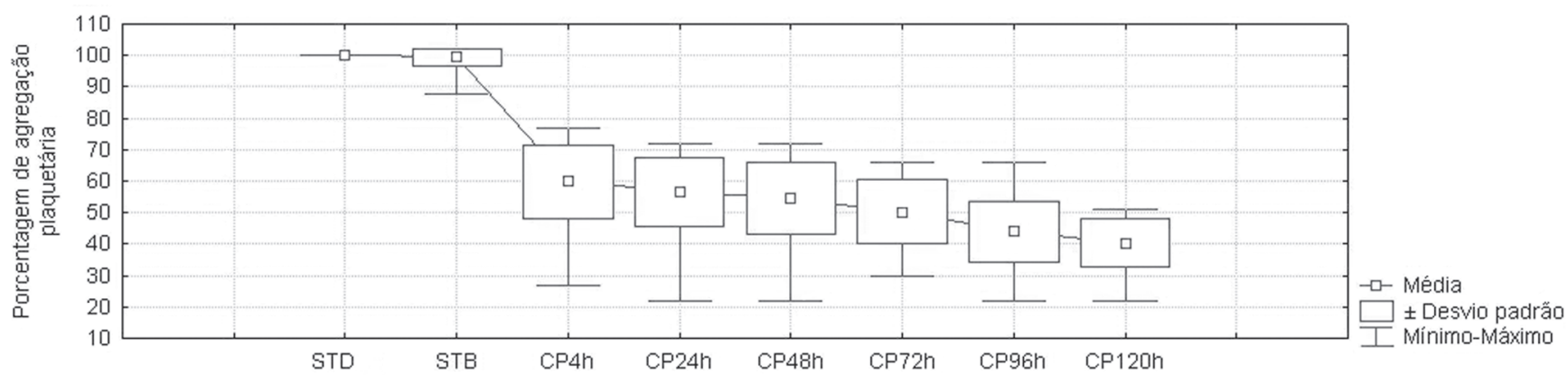

Figura 1. Comportamento da agregação plaquetária de 33 doadores, com os agonistas AA e ADR, nos plasmas ricos em plaquetas obtidos do STD, do STB e dos CP, nos vários tempos de estocagem, em horas 


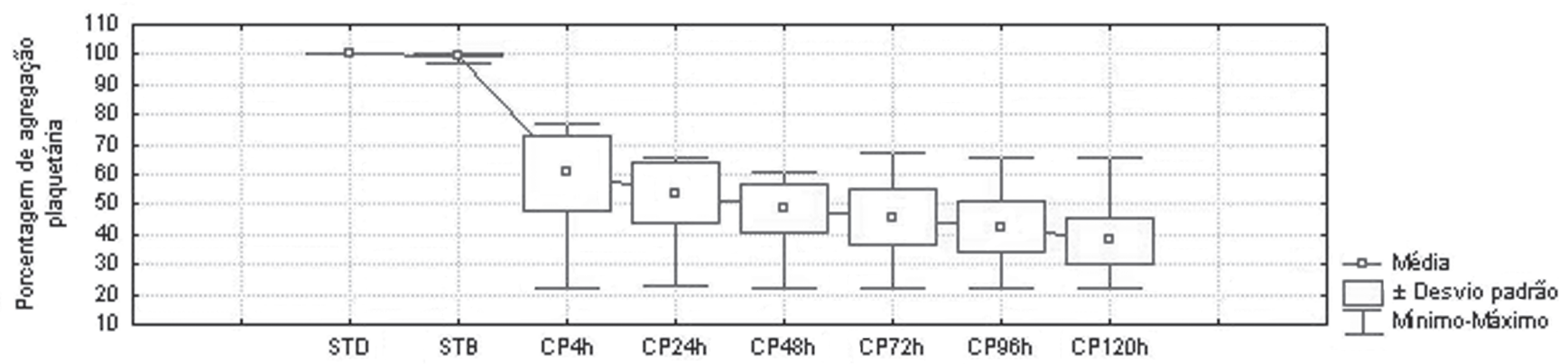

Figura 2. Comportamento da agregação plaquetária de 33 doadores, com os agonistas AA e ADP, nos plasmas ricos em plaquetas obtidos do STD, do STB e dos CP, nos vários tempos de estocagem, em horas

Tabela 2 . Medidas descritivas do número de plaquetas $\times 10^{10} / 70 \mathrm{~mL}$ (média e desvio padrão; valor mínimo, mediana e valor máximo), dos $33 \mathrm{CP}$, nos vários tempos de estocagem, em horas, e resultados do teste de Duncan

\begin{tabular}{ccccccc}
\hline & CP4h & CP24h & CP48h & CP72h & CP96h & CP120h \\
\cline { 2 - 7 } & $7,5 \pm 0,3$ & $7,2 \pm 0,3$ & $7,0 \pm 0,3$ & $6,8 \pm 0,4$ & $6,6 \pm 0,4$ & $6,3 \pm 0,3$ \\
& $6,9(7,6) 8,0$ & $6,3(7,2) 7,6$ & $6,3(7,0) 7,6$ & $6,1(6,9) 7,4$ & $5,9(6,7) 7,0$ & $5,6(6,3) 7,0$ \\
\hline CP4h & - & $<0,01$ & $<0,01$ & $<0,01$ & $<0,01$ & $<0,01$ \\
CP24h & - & - & $<0,01$ & $<0,01$ & $<0,01$ & $<0,01$ \\
CP48h & - & - & - & $<0,01$ & $<0,01$ & $<0,01$ \\
CP72h & - & - & - & - & $<0,01$ & $<0,01$ \\
CP96h & - & - & - & - & - & $<0,01$ \\
\hline
\end{tabular}

Média \pm Desvio padrão

Mínimo (mediana) Máximo

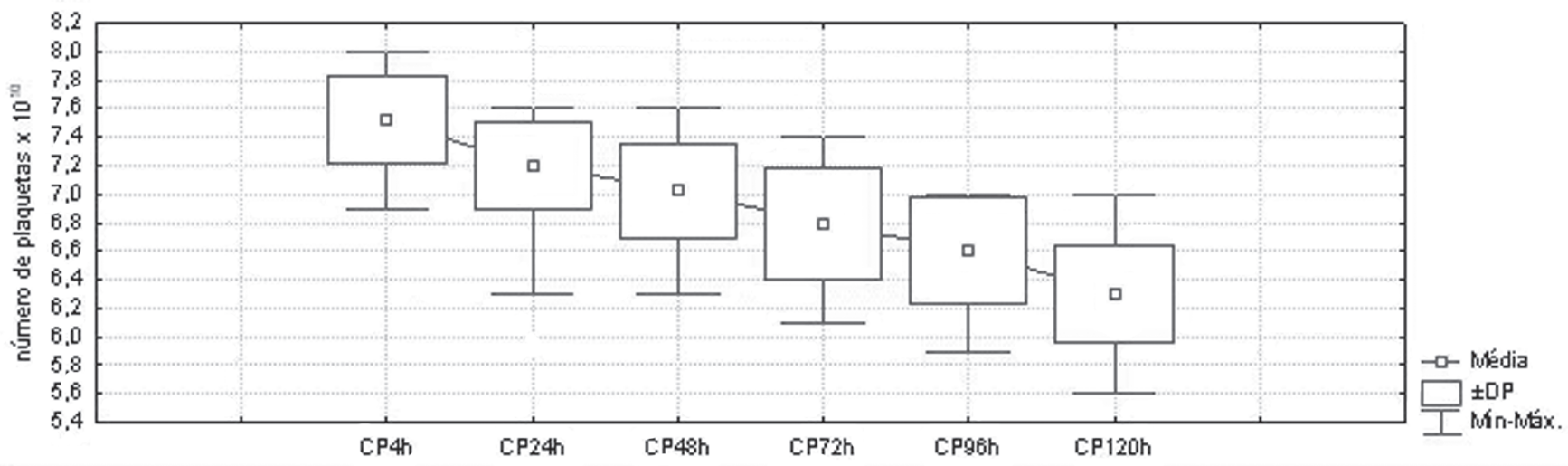

Figura 3. Comportamento do número de plaquetas $\times 10^{10 / 70 ~} \mathrm{~mL}$ dos $33 \mathrm{CP}$, nos vários tempos de estocagem, em horas $\operatorname{dos} C P$

$p \mathrm{O}_{2}, p \mathrm{CO}_{2}$, $\mathrm{pH}$ e concentração de sódio e de potássio

Observaram-se progressivos aumento da $\mathrm{pO}_{2}$, de 123,20 $( \pm 11,39) \mathrm{mmHg}$ às 4 horas para $147,30( \pm 16,59) \mathrm{mmHg}$ às 120 horas, e diminuição da $\mathrm{pCO}_{2}$, de $67,20( \pm 6,55) \mathrm{mmHg}$ às 4 horas para 22,00 $( \pm 4,87) \mathrm{mmHg}$ às 120 horas, ambos estatisticamente significantes, com teste de Duncan sempre $<0,013$. Houve também aumento estatisticamente significante do $\mathrm{pH}$, que passou de $7,1( \pm 0,04)$ às 4 horas para $7,2( \pm 0,08)$ às 120 horas $(\mathrm{p}<0,01)$. As concentrações dos eletrólitos aumenta- ram gradualmente ao longo das 120 horas de estocagem, sendo que o sódio aumentou de $155,0( \pm 1,0) \mathrm{mEq} / \mathrm{L}$ para 155,8 $( \pm 1,3) \mathrm{mEq} / \mathrm{L}$ e o potássio de $2,6( \pm 0,34) \mathrm{mEq} / \mathrm{L}$ para 2,8 $( \pm 0,3) \mathrm{mEq} / \mathrm{L}$, aumentos estes estatisticamente significantes $(\mathrm{p}<0,01)$.

\section{Aspecto visual}

O swirling esteve presente em todos os $\mathrm{CP}$ e em apenas um foi notada a presença de grumos. Não foram detectadas as presenças de hemácias e de lipemia nos $33 \mathrm{CP}$ estudados. 


\begin{tabular}{|c|c|c|c|c|c|c|c|c|}
\hline $\begin{array}{l}\text { Tempo de } \\
\text { estocagem }\end{array}$ & & $\begin{array}{c}1 / \log \# \\
N P\end{array}$ & $\mathrm{pH}$ & pO2 & $\begin{array}{l}1 / \log \# \\
\mathrm{pCO} 2\end{array}$ & $\begin{array}{c}1 / \log \# \\
{[\mathrm{Na}]}\end{array}$ & {$[\mathrm{K}]$} & $\mathrm{NL}$ \\
\hline \multirow[t]{2}{*}{$4 \mathrm{~h}$} & $r$ & 0,03 & 0,21 & $-0,14$ & 0,14 & $-0,36^{\star}$ & $-0,47^{\star}$ & 0,05 \\
\hline & $p$ & 0,85 & 0,23 & 0,45 & 0,45 & $0,04^{*}$ & $0,01^{*}$ & 0,79 \\
\hline \multirow[t]{2}{*}{$24 \mathrm{~h}$} & $r$ & 0,19 & $-0,26$ & $-0,31^{*}$ & $-0,40^{*}$ & $-0,26$ & $-0,48^{*}$ & $-0,35^{\star}$ \\
\hline & $p$ & 0,28 & 0,14 & $0,04^{*}$ & $0,00^{*}$ & 0,15 & $0,00^{*}$ & $0,04^{*}$ \\
\hline \multirow[t]{2}{*}{$48 \mathrm{~h}$} & $r$ & $-0,02$ & $-0,20$ & $-0,37^{*}$ & $-0,30^{*}$ & $-0,37^{*}$ & $-0,31$ & $-0,15$ \\
\hline & $p$ & 0,92 & 0,27 & $0,03^{*}$ & $0,04^{*}$ & $0,03^{*}$ & 0,08 & 0,40 \\
\hline \multirow[t]{2}{*}{$72 \mathrm{~h}$} & $r$ & 0,08 & 0,11 & $-0,52^{\star}$ & $-0,18^{*}$ & $-0,13^{\star}$ & 0,14 & 0,09 \\
\hline & $p$ & 0,92 & 0,55 & $0,00^{\star}$ & $0,03^{\star}$ & $0,04^{*}$ & 0,45 & 0,62 \\
\hline \multirow[t]{2}{*}{$96 \mathrm{~h}$} & $r$ & $-0,23$ & $-0,40^{*}$ & $-0,64^{\star}$ & $-0,40^{*}$ & $-0,59^{\star}$ & $-0,25$ & 0,06 \\
\hline & $p$ & 0,20 & $0,02^{*}$ & $0,00^{*}$ & $0,02^{*}$ & $0,00^{*}$ & 0,16 & 0,76 \\
\hline \multirow[t]{2}{*}{$120 \mathrm{~h}$} & $r$ & $-0,40^{*}$ & $-0,46^{*}$ & $-0,66^{*}$ & $-0,46^{*}$ & $-0,66^{\star}$ & $-0,39^{*}$ & $-0,21$ \\
\hline & $p$ & $0,02^{*}$ & $0,00^{*}$ & $0,00^{*}$ & $0,00^{*}$ & $0,00^{*}$ & $0,03^{*}$ & 0,24 \\
\hline
\end{tabular}

${ }^{*} p<0,05$ e respectivas correlações; $r$ - coeficiente de correlação linear; $p$ - nível de significância \# - Os valores de $r$ têm sinais correspondentes aos dados transformados $(1 / \mathrm{log})$; NP - número de plaquetas $\times 10^{10} / 70 \mathrm{ml}$ dos concentrados de plaquetas (CP); NI - número de leucócitos $\times 10^{8} / \mathrm{mm}^{3}$ dos concentrados de plaquetas (CP); [Na] - concentração de sódio; [K] - concentração de potássio

\section{Cultura para bactérias}

Não houve crescimento de microrganismos em nenhum dos 33 CP estudados.

\section{Correlações}

As correlações entre os índices de agregação plaquetária com o par de agonista AA/ADR (mais freqüentemente significantes do ponto de vista estatístico) foram negativas com a pO ${ }_{2}$, em geral positivas com a $\mathrm{pCO}_{2}$ e positivas com a concentração do sódio, enquanto as correlações com a concentração de plaquetas e de leucócitos, $\mathrm{pH}$ e concentração de potássio foram fracas e raramente significantes do ponto de vista estatístico. Quadro 1. Resultados bastante similares foram observados com os agonistas AA/ADP (resultados não mostrados).

\section{Discussão}

Não observamos agregação espontânea das plaquetas em nenhum dos momentos analisados, o que está de acordo com dados da literatura. ${ }^{14-17}$ As agregações plaquetárias com os dois pares de agonistas (AA/ADR e AA/ADP) foram muito semelhantes entre si, e valores próximos de $100 \%$ no STD e no STB mostram que o processo de coleta não interferiu de maneira significativa na função plaquetária. Ressalte-se que a coleta foi feita rigorosamente de acordo com as normas do Ministério da Saúde. ${ }^{5}$ Por outro lado, a agregação plaquetária de $60 \%$ quatro horas após a produção do CP e de $40 \%$ no quinto dia de estocagem (120 horas) demonstra que o processo de fracionamento foi o maior responsável pela diminuição da função in vitro das plaquetas.
Em outros estudos da função in vitro de plaquetas, obtidas pelo método do PRP, foram utilizados na agregação os agonistas ADP, colágeno, epinefrina e ristocetina isolados, ${ }^{15} \mathrm{ADP}$ e colágeno isolados ${ }^{16,18}$ ou associados ${ }^{16,17} \mathrm{e}$ trombina e colágeno isolados. ${ }^{19} \mathrm{Em}$ nenhum deles os processos de coleta e de fracionamento foram avaliados separadamente como no presente estudo. Os resultados encontrados após a coleta/produção nessas pesquisas variaram de $93 \%$ a $37 \% .{ }^{15-19}$ Outro estudo de função plaquetária, empregando colágeno, ADP e adrenalina isoladamente, ${ }^{20}$ obteve, do sangue colhido diretamente dos doadores, índices de agregação de $70 \%, 45 \%$ e $40 \%$, respectivamente. Ao final do período de estocagem, estes índices, após queda de $8 \%, 10 \% \mathrm{e}$ $18 \%$, responsabilizada à coleta e processamento, alcançaram níveis de agregação tão baixos quanto $15 \%, 4 \%$ e $3 \%$, respectivamente. Contudo, a comparação dos nossos resultados com os desses trabalhos é limitada, pois as metodologias foram diversas da nossa e nenhuma delas avaliou, separadamente, a influência da coleta e da produção. Ressalte-se que, diferentemente dessas pesquisas, usamos os agonistas aos pares no teste de agregação, o que produz resposta mais satisfatória do que seu uso isolado. $^{21}$

Embora a queda da agregação plaquetária dos $\mathrm{CP}$ possa ser revertida in vivo 24 horas após a transfusão, ${ }^{22}$ a prevenção das alterações induzidas pela estocagem poderia levar as plaquetas a funcionarem melhor já imediatamente após a infusão. ${ }^{23}$ Portanto, nossos resultados sugerem que o processo de produção pode ter importante papel na qualidade hemostática dos CP. 
A queda estatisticamente significante da concentração de plaquetas ao longo das 120 horas de estocagem pode ser explicada pela formação de microagregados plaquetários ou pela lise das plaquetas. A formação de microagregados é a principal razão para a redução da concentração de plaquetas após estocagem, como observado em diferentes estudos. ${ }^{24,25}$ Apesar da diminuição da concentração de plaquetas, $100 \%$ dos $\mathrm{CP}$ apresentaram, ao final do período de estocagem, valores acima dos níveis mínimos recomendados pelas normas técnicas brasileiras. ${ }^{5}$ Ademais, não houve correlação da concentração de plaquetas com o teste de agregação, desvinculando, pelo menos em parte, relação de causa e efeito entre ambos, como já observado em estudo similar. ${ }^{19}$

Quanto aos leucócitos residuais, sempre abaixo dos limites máximos estabelecidos pelas normas técnicas brasileiras, ${ }^{5}$ apresentaram queda estatisticamente significantes em relação aos valores iniciais (4 horas) já a partir das 24 horas de estocagem. A inexistência de correlação entre concentração de leucócitos e agregação plaquetária, contrariando a literatura, possivelmente possa ser explicada pelo reduzido número destes em nossos concentrados. Com relação aos eletrólitos (sódio e potássio), apesar do discreto aumento de ambos durante a estocagem, estiveram sempre com níveis compatíveis com o uso terapêutico dos $\mathrm{CP}^{30} \mathrm{e}$ apenas o sódio apresentou correlação com a agregação plaquetária.

$\mathrm{O}$ aumento da $\mathrm{pO}_{2}$ e a queda da $\mathrm{pCO}_{2}$, gradativos e estatisticamente significantes $(\mathrm{p}<0,05)$, indica boa troca gasosa durante a estocagem, ${ }^{16,26}$ demonstrando a não interferência destes gases nos índices de queda da agregação plaquetária. Embora tenhamos encontrado correlação entre os valores de agregação plaquetária e a $\mathrm{pO}_{2}$ e $\mathrm{pCO}_{2}$, isto não significa necessariamente que haja relação de causa e efeito entre esses parâmetros. De fato, se houvesse tal relação entre as variáveis em questão, menores valores de agregação deveriam se associar a menores valores de $\mathrm{pO}_{2}$ e maiores de $\mathrm{pCO}_{2},{ }^{27}$ quando exatamente o oposto foi observado no presente estudo.

Apesar do aumento gradativo do $\mathrm{pH}$, estatisticamente significante a partir das 98 horas de estocagem, o teste de correlação demonstrou que este aumento não acompanhou a queda dos valores da agregação. Portanto, há evidências de que as alterações do $\mathrm{pH}$ não foram responsáveis pela queda da função plaquetária in vitro, até mesmo porque os valores observados (entre 7,0 e 7,4) são considerados adequados a uma boa preservação dos CP.

A presença do swirling em todas as bolsas, durante os cinco dias de estocagem, são também evidências da adequada qualidade dos concentrados plaquetários. ${ }^{3,5}$ Em apenas uma bolsa foi observada a presença de grumos, verificada logo após a produção do CP (4h), que foi acompanhada de agregação de $22 \%$ (valor praticamente inalterado até o fim da estocagem), porém mantendo os demais parâmetros dentro dos níveis normais. Portanto, estas alterações parecem se dever ao processo de produção do respectivo CP. Também a ausência de hemácias e de lipemia e a negatividade das culturas atestam a boa qualidade dos CP estudados. ${ }^{5}$

\section{Conclusão}

Os resultados do presente estudo sugerem que, ainda que se obedeça rigorosamente os procedimentos operacionais padrões (POP) na obtenção dos concentrados plaquetários de unidades individuais pelo método do PRP, o controle de qualidade deve contemplar, individualmente, cada etapa do processo, ou seja, a coleta, o fracionamento e todo período de estocagem deste hemocomponente.

\begin{abstract}
As quality control of platelet concentrates obtained at the expiration date does not distinguish between the different stages that may cause reductions in quality, such as collection and storage, we decided to separately investigate the influence of collection, processing and storage on the quality of these blood components. This study evaluated 33 random platelet concentrates daily for five days for the following parameters: aggregation, number of platelets and leukocytes, PO2 and $\mathrm{PCO} 2, \mathrm{pH}$, sodium and potassium, the presence of swirling, platelet clots, red blood cells and lipemia, and bacteria culture. We observed a greater decrease in platelet aggregation with pairs of agonists during the production of platelet concentrates (from $99.4 \%$ to $59.8 \%, p<0.05)$, followed by a gradual drop during storage reaching $40.4 \%$ on day five. During storage the following were also observed: 1. a gradual drop of platelet concentration $(p<0.05)$ although the values always remained higher than $5 \times 1010 / 70 \mathrm{~mL} ; 2$. a decrease in leukocyte concentration $(p<0.05)$; 3. increases in $p O 2$ and decreases in $p C O 2(p<0.05) ; 4$. increase in the $p H(p<0.05$ from day 4) and in concentrations of sodium and potassium (in general p<0.05); 5. swirling in all platelet concentrations, platelet clots in only one and absence of red blood cells and lipemia in all; and 6. negative cultures for bacteria. The results showed more apparent changes in the production process and suggest that the quality control of platelet concentrations should encompass all stages, from collection to the end of the storage period. Rev. Bras. Hematol. Hemoter. 2008;30(5):367-373.
\end{abstract}

Key words: Platelet transfusion; platelet aggregation; quality control.

\section{Referências Bibliográficas}

1. White JG.. Current concepts of platelet structure. Am J Clin Pathol. 1979;71(4):363-78.

2. Rebulla P. Revisitation of the clinical indications for the transfusion of platelet concentrates. Rev Clin Exp Hematol. 2001;5(3):288-310.

3. Rebulla P. In vitro and in vivo properties of various types of platelets. Vox Sang. 1998;74 Suppl 2:217-22.

4. Krishnan LK, Mathai J, Sulochana PV, Jacob J, Sivakumar R. Biochemical lesions of platelets stored as concentrates in PVC bags. Indian J Med Res. 1997;105:85-92. 
5. Brasil. Ministério da Saúde. Resolução RDC 153, de 14 de junho de 2004. Determina o Regulamento Técnico para os procedimentos hemoterápicos, incluindo a coleta, o processamento, a testagem, o armazenamento, o transporte, o controle de qualidade e o uso humano de sangue, e seus componentes, obtidos do sangue venoso, do cordão umbilical, da placenta e da medula óssea. D.O.U., Brasília, DF, 24 jun; 2004.

6. Conep (Comissão Nacional de Ética em Pesquisa). Disponibiliza informações sobre instituições que têm registro de Comitê de Ética em Pesquisa na Conep (até dezembro de 2006). Disponível em: $<$ http://conselho.saude.gov.br/comissao/conep/2006/ cepsapravados. doc > Acesso em:29 nov. 2007.

7. Born GV, Cross MJ. The aggregation of blood platelets. J Physiol. 1963;168:178-95

8. Bicalho JA. Análise comparativa de métodos para contagem de plaquetas em concentrado de plaquetas. In: XVII Congresso Nacional do Colégio Brasileiro de Hematologia 1999, Foz do Iguaçu. Série de Monografia da Escola Brasileira de Hematologia. 1999; 6:1-31.

9. Walker HR. Blood components: preparation, storage and shipment. In: Walker, H. R. Technical Manual Library of Congress. 11. ed. American Association of Blood Banks. 1993:63-4.

10. Which are the parameters to be controlled in platelet concentrates in order that they may be offered to the medical profession as a standardized product with specific properties? Vox Sang. 1981; 40(2):115-26.

11. Tandy NP, Taylor MA. Platelet concentrates for transfusion: control of production and storage. Med Lab Sci. 1980;37 (2): 127-36.

12. Bertolini F, Murphy S. A multicenter inspection of the swirling phenomenon in platelet concentrates prepared in routine practice. Biomedical Excellence for Safer Transfusion (BEST) Working Party of the International Society of Blood Transfusion. Transfusion. 1996;36(2):128-32.

13. Holme S. Storage and quality assessment of platelets. Vox Sang. 1998;74 Suppl 2:207-16.

14. McGill M. Temperature cycling preserves platelet shape and enhances in vitro test scores during storage at 4 degrees. J Lab Clin Med. 1978;92(6):971-82.

15. Kocazeybek B, Arabaci U, Akdur H, Sezgiç M, Erentürk S. Prospective evaluation of platelets prepared by single and random methods during 5 days of storage: aspects related to quality and quantity. Transfus Apher Sci. 2002;26(1):29-34.

16. Lippa S, Mores N, Aureli V, Fagiolo E. Biochemical and functional changes of platelet stored for transfusional use. Folia Haematol Int Mag Klin Morphol Blutforsch. 1987;114(5):680-5

17. Shimizu T, Shibata K, Kora S. Plasma-depleted platelet concentrates prepared with a new washing solution. Vox Sang. 1993; 64(1): 19-23.

18. Connor J, et al. Recovery of in vitro functional activity of platelet concentrates stored at 4 degrees $\mathrm{C}$ and treated with secondmessenger effectors. Transfusion. 1996;36(8):691-8.

19. Neiva TJC, Machado MJ, Hoehn, M, Hermes EM, Vituri CLV, Ferreira JS, et al. Evaluation of platelet aggregation in platelet concentrates (PCs): storage implications. Rev Bras Hematol Hemoter. 2003;25:207-12.

20. Neiva TJC, Brocardo G, Ferreira JS, Ferreira VL, Castro CES. Avaliação da função plaquetária de doadores de sangue. Rev Bras Anál Clín. 2000;32:249-52.

21. DiMinno G, Silver MJ, Murphy S. Stored human platelets retain full aggregation potential in response to pairs of aggregating agents. Blood. 1982;59(3):563-8.

22. Murphy S, Gardner FH. Platelet storage at 22 degrees C; metabolic, morphologic, and functional studies. J Clin Invest. 1971; 50(2):370-7
23. Moroff G. Aggregation: release response of platelets stored at 22 degrees C. Vox Sang. 1981;40 Suppl 1:110-4

24. Koerner K. Platelet function of room temperature platelet concentrates stored in a new plastic material with high gas permeability. Vox Sang. 1984;47(6):406-11.

25. Krishnan LK, Sulochana PV, Mathai J, John A, Sivakumar R. Morphological \& ultrastructural changes of platelet concentrates stored in PVC bags. Indian J Med Res. 1997 Feb;105:77-84.

26. Murphy S, Kahn RA, Holme S, Phillips GL, Sherwood W, Davisson $\mathrm{W}$, et al. Improved storage of platelets for transfusion in a new container. Blood. 1982;60(1):194-200.

27. Fratantoni JC. Review: the platelet storage lesion: possible role of plasticizers? Blood Cells. 1992;18(3):435-40.

28. White JG. Long-term storage of functional platelets in vitro. Vox Sang. 1981;40 Suppl 1:119-22.

29. Solberg C, Holme S, Little C. Morphological changes associated with $\mathrm{pH}$ changes during storage of platelet concentrates in firstgeneration 3-day container. Vox Sang. 1986;50(2):71-7.

30. Böck M, Glaser A, Pfosser A, Schleuning M, Heim MU, Mempel W. Storage of single-donor platelet concentrates: metabolic and functional changes. Transfusion. 1993 Apr;33(4):311-5.

Avaliação: Editor e dois revisores externos Conflito de interesse: não declarado

Recebido: 29/11/2007

Aceito após modificações: 31/03/2008 